\title{
Growth and neurodevelopmental status in patients with retinopathy of prematurity treated with intravitreal bevacizumab: a case- control study
}

\author{
Majid Abrishami ${ }^{1}$, Hassan Boskabadi ${ }^{2}$, Mojtaba Abrishami ${ }^{1}$, Farid Shekarchian ${ }^{1}$, Majid Khadem-Rezaiyan ${ }^{3}$ and \\ Nasser Shoeibi i* (B)
}

\begin{abstract}
Background: The current study aimed to evaluate growth and neurodevelopmental status in patients with retinopathy of prematurity (ROP) treated with intravitreal bevacizumab (IVB).

Methods: This historical cohort study was conducted on neonates with ROP who were treated with IVB and age and birth weight-matched controls who did not need IVB. Apgar score less than five, history of blood transfusion and history of infectious diseases were among exclusion criteria. Indirect ophthalmoscopic examinations were performed till complete retinal vascularization. Growth and neurodevelopmental status were evaluated by Age and Stages Questionnaire (ASQ) at the ages of 6, 12, and 18 months. Developmental milestones were assessed in five areas (gross motor, fine motor, personal-social status, problem-solving, and relationship) and overall issues.

Results: A total of 34 cases and 36 controls were included in the present study. Birth weight and corrected gestational age were not statistically different between the groups. In a follow-up period of 18 months, bevacizumab was effective as a primary treatment in the treatment of severe cases of ROP. There was no significant difference between the two groups regarding the five areas and overall issues in follow-up intervals $(P>0.05)$.
\end{abstract}

Conclusions: The obtained results did not show any growth and neurodevelopmental differences between treatment-naïve infants and those receiving IVB for the treatment of ROP.

Keywords: Retinopathy of prematurity, Growth, Neurodevelopmental status, Bevacizumab, Retina

\section{Background}

Retinopathy of prematurity (ROP) accounts for $4 \%$ and up to $40 \%$ of all cases of childhood blindness in developed and developing countries, respectively [1] The following factors increase the risk of this disease: gestational age of 32 weeks or less, weight of less than $1250 \mathrm{~g}$, intrauterine

*Correspondence: shoeibin@mums.ac.ir

${ }^{1}$ Eye Research Center, Mashhad University of Medical Sciences, Qarani Blvd, 9195965919 Mashhad, Iran

Full list of author information is available at the end of the article growth retardation, and exposure to supplemental oxygen for a long time $[2,3]$.

Retinal vascularization originates from the optic disc at about 16 weeks of gestation [4]. The blood vessels grow gradually toward the periphery of the developing retina to supply oxygen and nutrients. At term gestation, the retinal vessel growth is almost complete, while in preterm neonates the normal pattern of vascularization is disrupted and may be interrupted. The peripheral area of the non-vascularized retina is at risk of oxygen deprivation [5]. Vascular endothelial growth original author(s) and the source, provide a link to the Creative Commons licence, and indicate if changes were made. The images or other third party material in this article are included in the article's Creative Commons licence, unless indicated otherwise in a credit line to the material. If material is not included in the article's Creative Commons licence and your intended use is not permitted by statutory regulation or exceeds the permitted use, you will need to obtain permission directly from the copyright holder. To view a copy of this licence, visit http://creativecommons.org/licenses/by/4.0/. The Creative Commons Public Domain Dedication waiver (http://creativeco mmons.org/publicdomain/zero/1.0/) applies to the data made available in this article, unless otherwise stated in a credit line to the data. 
factor (VEGF) is the major growth factor which is responsible for angiogenesis, and high levels of VEGF level is considered to be the primary angiogenic factor mediating retinal neovascularization in eyes with ROP [5]. The studies conducted on patients with stage 3 and 4 ROP demonstrated that the vitreous concentration of VEGF was significantly higher, compared to that in eyes with inactive ROP $[6,7]$.

Bevacizumab (Avastin; Genentech Inc., South San Francisco, California, USA) as an anti-VEGF has shown the beneficial effect for zone I or II posterior stage 3 with plus disease retinopathy of prematurity [8]. Although intravitreal bevacizumab (IVB) is off-label in ROP treatment, the advantages of IVB for ROP include ongoing retinal vascularization, the short duration of the procedure, and the absence of anesthesia [4, 8]. Nonetheless, bevacizumab enters the general circulation after IVB injection, may suppress plasma VEGF levels, and can be detected in the blood for 8 weeks in patients with type 1 ROP [9-11].

Owing to the necessity of VEGF for normal angiogenesis, as well as its neuroprotective and growth effects, the present study was conducted to assess the developmental status in infants who underwent intravitreal bevacizumab injection for the treatment of ROP.

\section{Methods}

\section{Study participants}

This historical cohort study was performed at Khatam Eye Hospital, a referral ROP center in Northeast Iran. The consecutive patients with a diagnosis of bilateral type 1 ROP who needed bilateral IVB injection $(0.625 \mathrm{mg} / 0.025 \mathrm{~mL})$ confirmed by two retina specialists were included. The exclusion criteria at the time of patient and control selection entailed: (1) a history of intracranial hemorrhage, (2) Apgar score less than five, (3) birth weight more than 1500, (4) gestational age more than 33 weeks, (5) any history of blood transfusion, (6) any history of TORCH syndrome, and (7) other infectious systemic diseases affecting the central nervous system. The gestational age-matched control cohort was comprised of premature neonates who were followed up in the same center and they did not need IVB for retinal vascularization because of of insufficient severity. Detailed ocular and systemic histories were obtained from each subject. The ophthalmic examinations were performed based on a predetermined schedule according to guidelines provided by the American Academy of Pediatrics using RetCam (Clarity Medical Systems, Pleasanton, CA USA) and indirect ophthalmoscopy till complete retinal vascularization reached the ora serrata.

\section{Ages and stages questionnaire}

Growth and development of the selected patients and control group were evaluated by one neonatologist (H.B.) using general examination, past medical history, gestational and birth history, as well as Ages and Stages Questionnaire (ASQ) assessment. Date of birth, height, weight, and head circumference was registered and assessed on every pediatric examination at 6,12 , and/ or 18 months of corrected age.

The ASQ, which was used for the assessment of developmental status, is one of the most widely used parent-completed questionnaires that pinpoints developmental progress in children between the ages of 1 month to $5 \frac{1}{2}$ years [12]. ASQ measures developmental milestones in five areas (communication, fine motor, gross motor, problem solving ability, and personalsocial functioning). Parents complete the questionnaire, indicating for each item "yes" if child performs the item, "sometimes" indicating an occasional or emerging skill, or "not yet" indicating that the child does not yet perform the behavior. Responses to the six questions in each area are added to calculate a score for each area. Scores for each area should fall between 0 and 60 (Yes $=10$ points, Sometimes $=5$ points, Not yet $=0$ points). Higher scores indicate more positive outcomes. Each area of the ASQ has different cutoff scores. If the baby's score in each area and the total score is above the cutoff point, baby's development is considered to be on schedule. This test performs well with children with prematurity $[13,14]$. It has been proven to be a reliable and valid screening test even in its translated and culturally-adapted versions. This questionnaire has been adapted, validated, and standardized in the population studied [15]. The mean score was calculated for score calculation of every aspect due to the different number of items in various aspects of ASQ. Head circumference and weight gain were also included in the assessment. In our study, a neonatologist supervised the filling of questioners by parents.

\section{Statistical analysis}

The normal distribution of variables was examined using the Kolmogorov-Smirnov test. Qualitative variables were expressed using percentages. T-test, ANOVA (or Mann-Whitney's test and the Kruskal-Wallis test as non-parametric equivalent tests, respectively) and chi-square test were used for inferential statistics. The level of statistical significance was set at 0.05 . All statistical analyses were performed using SPSS software (version 11.5) (IBM SPSS Statistics, IBM Corporation, Chicago, IL, USA). 


\section{Ethical considerations}

The study protocol adhered to the tenets of the Declaration of Helsinki. Parents of all participants provided written informed consent before enrollment, and the ethical aspects of the study were approved by the Regional Committee on Medical Ethics at Mashhad University of Medical Sciences, Mashhad, Iran (IR. MUMS.REC.1393.78).

\section{Results}

A total of 34 cases (19 males) and 36 gestational agematched control neonates (20 males) with ROP of insufficient severity to require intervention, were recruited in the study from January 2015 to January 2016. There was no significant difference between the two groups regarding supplemental oxygen therapy $(\mathrm{p}=0.064)$ or duration of neonatal intensive care unit (NICU) stay $(\mathrm{p}=0.455)$. Weight and head circumference data at birth, as well as 6,12 , and 18 months in both groups are presented in Table 1.

Gestational age $(P=0.121)$ and gender $(P=0.584)$ did not show significant difference between the two groups. The most severe stage of retinopathy was at the postconceptional age of $37.15 \pm 4.46$ weeks in the treatment group and $38.32 \pm 3.35$ in the control group $(\mathrm{p}=0.230)$. Other Demographic characteristics of two groups are presented in Table 2.

There was no significant difference between the two groups regarding overall ASQ scores. The mean overall scores were obtained $1.16 \pm 10.34,1.03 \pm 0.24$, and $1.30 \pm 0.28$ at 6,12 , and 18 months in the case group, respectively. On the other hand, these values were reported as $1.09 \pm 0.15,0.08 \pm 0.26$, and $1.20 \pm 0.31$ at 6,12 , and 18 months in the control group, respectively. These scores did not show significant difference; moreover, the scores were not statistically different between cases and controls in the five areas of the questionnaire

Table 1 Weight and head circumference exam time points (mean \pm standard deviation)

\begin{tabular}{lllll}
\hline & \multicolumn{4}{l}{ Exam time point (corrected post-gestational age) } \\
\cline { 2 - 5 } & Birth & $\mathbf{6}$ month & $\mathbf{1 2}$ month & 18 month \\
\hline Weight (Kg) & & & \\
Case & $1.23 \pm 0.05$ & $8.03 \pm 0.39$ & $9.18 \pm 0.24$ & $10.53 \pm 0.57$ \\
Control & $1.35 \pm 0.04$ & $7.06 \pm 0.21$ & $9.35 \pm 0.23$ & $10.45 \pm 0.65$ \\
P value & 0.071 & 0.043 & 0.609 & 0.933 \\
Head circumference $(\mathrm{cm})$ & & & \\
Case & $26.36 \pm 0.62$ & $43.15 \pm 0.43$ & $44.59 \pm 0.34$ & $45.93 \pm 0.69$ \\
Control & $28.08 \pm 0.33$ & $42.42 \pm 0.50$ & $45.33 \pm 0.26$ & $46.00 \pm 1.08$ \\
P value & 0.027 & 0.279 & 0.088 & 0.960 \\
\hline
\end{tabular}

Table 2 Demographic characteristics of groups

\begin{tabular}{|c|c|c|c|}
\hline Characteristic & Case & Control & P value \\
\hline \multicolumn{4}{|l|}{ Fertilization } \\
\hline Normal & $20(74 \%)$ & $21(75 \%)$ & 0.591 \\
\hline IVF & $7(26 \%)$ & $7(25 \%)$ & \\
\hline \multicolumn{4}{|l|}{ Delivery } \\
\hline Normal & $11(32 \%)$ & $8(23 \%)$ & 0.270 \\
\hline Cesarean & $23(68 \%)$ & $27(77 \%)$ & \\
\hline \multicolumn{4}{|l|}{ Pregnancy } \\
\hline Single & $16(47 \%)$ & $13(36 \%)$ & 0.246 \\
\hline Multiple & $18(53 \%)$ & $23(64 \%)$ & \\
\hline Gestational age (weeks) & $28.79 \pm 1.96$ & $29.86 \pm 1.93$ & 0.021 \\
\hline NICU stay (days) & $26.17 \pm 14.47$ & $28.08 \pm 15.90$ & 0.455 \\
\hline $\mathrm{O}_{2}$ therapy (days) & $24.80 \pm 15.90$ & $18.00 \pm 10.27$ & 0.064 \\
\hline
\end{tabular}

Table 3 Mean score of each area of ASQ for different ages in the case and control group

\begin{tabular}{|c|c|c|c|c|}
\hline \multirow[t]{2}{*}{ Area } & \multicolumn{3}{|c|}{$\begin{array}{l}\text { Exam time point (corrected post- } \\
\text { gestational age) }\end{array}$} & \multirow{2}{*}{$\begin{array}{l}\text { P value } \\
\text { (between } \\
\text { two groups) }\end{array}$} \\
\hline & 6 month & 12 month & 18 month & \\
\hline \multicolumn{5}{|c|}{ Communication } \\
\hline Case & $1.80 \pm 0.17$ & $1.68 \pm 0.41$ & $1.72 \pm 0.34$ & 0.168 \\
\hline Control & $1.55 \pm 0.48$ & $1.74 \pm 0.36$ & $1.58 \pm 0.46$ & \\
\hline P value & 0.047 & 0.594 & 0.463 & \\
\hline \multicolumn{5}{|c|}{ Gross motor } \\
\hline Case & $1.39 \pm 0.46$ & $1.55 \pm 0.50$ & $1.83 \pm 0.39$ & 0.122 \\
\hline Control & $1.46 \pm 0.47$ & $1.57 \pm 0.66$ & $1.94 \pm 0.08$ & \\
\hline Pvalue & 0.691 & 0.874 & 0.507 & \\
\hline \multicolumn{5}{|l|}{ Fine motor } \\
\hline Case & $1.49 \pm 0.52$ & $1.79 \pm 0.29$ & $1.58 \pm 0.31$ & 0.275 \\
\hline Control & $1.69 \pm 0.47$ & $1.82 \pm 0.28$ & $1.68 \pm 0.26$ & \\
\hline P value & 0.275 & 0.773 & 0.520 & \\
\hline \multicolumn{5}{|c|}{ Problem solving } \\
\hline Case & $1.33 \pm 0.38$ & $1.72 \pm 0.37$ & $1.67 \pm 0.31$ & 0.469 \\
\hline Control & $1.55 \pm 0.58$ & $1.77 \pm 0.39$ & $1.80 \pm 0.16$ & \\
\hline Pvalue & 0.261 & 0.684 & 0.373 & \\
\hline \multicolumn{5}{|c|}{ Social-personal } \\
\hline Case & $1.60 \pm 0.45$ & $1.58 \pm 0.43$ & $1.89 \pm 0.08$ & 0.627 \\
\hline Control & $1.65 \pm 0.48$ & $1.71 \pm 0.51$ & $1.83 \pm 0.21$ & \\
\hline P value & 0.795 & 0.265 & 0.518 & \\
\hline \multicolumn{5}{|l|}{ Overall } \\
\hline Case & $1.16 \pm 0.34$ & $1.03 \pm 0.24$ & $1.30 \pm 0.28$ & 0.512 \\
\hline Control & $1.09 \pm 0.15$ & $1.08 \pm 0.26$ & $1.20 \pm 0.31$ & \\
\hline$P$ value & 0.482 & 0.476 & 0.508 & \\
\hline
\end{tabular}



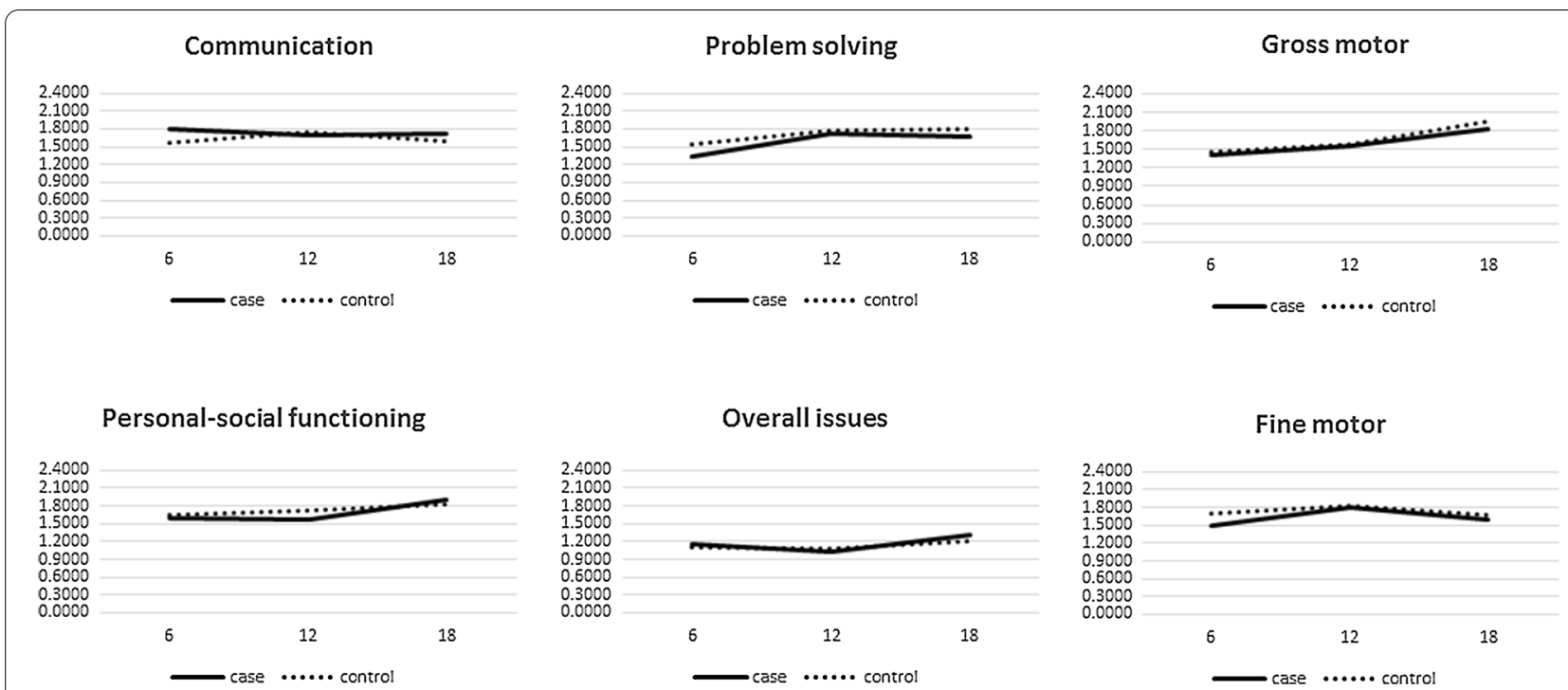

Fig. 1 Growth AND development process in six study aspects of ASQ at 6, 12 and 18 month old participants (X axis is the age of study participant and the $Y$ axis is the ASQ score in the related area)

(Table 3). Time course of measured data in each area of ASQ in both groups are summarized in Fig. 1.

\section{Discussion}

The present study assessed neonates with ROP who needed IVB and compared their growth and development status with those without IVB or any intervention. The obtained results did not find any differences between cases and premature neonates without a history of IVB; moreover, the IVB showed no effect on the developmental status till 18 months of age. Furthermore, no difference was observed between the two groups of treatment and control in terms of weight gain and head circumference till 18 months.

In patients with stage 3 ROP, laser photocoagulation and cryotherapy are the current destructive therapies, and visual field constriction is their important complication [8]. The IVB has been introduced as an effective treatment for type 1 ROP. It blocks the VEGF-A function which is shown to be an effective treatment in ROP [7-11].

BEAT-ROP (Bevacizumab Eliminates the Angiogenic Threat of Retinopathy of Prematurity) was a leading study on the effectiveness of bevacizumab in type 1 ROP [16]. There has been more interest in anti-VEGF therapy for ROP since then. However, there are many unanswered questions regarding long-term ocular and systemic adverse effects. The conventional dose of IVB in infants is half to one-fourth of adult dosages, demonstrating the relatively high dose of intravitreal anti-VEGF in preterm neonates $[17,18]$.
Blood-ocular barrier have been regarded as an effective barrier regarding the penetration of drug from the vitreous into the blood; nevertheless, recent studies have shown the escape of anti-VEGF into the blood circulation. For instance, Miyake et al. indicated that in primates, bevacizumab enters the general circulation, suppresses plasma VEGF levels, and can be detected in the blood for more than 8 weeks [11]. Sato et al. evaluated the level of bevacizumab and serum VEGF after IVB in ROP neonates and reported that the serum level of bevacizumab significantly increased over two weeks after the injection with an inverse decrement in the serum level of VEGF [10].

The inhibition of VEGF bioactivity in preterm neonates may affect normal ongoing growth and development in multiple organs while disrupting normal angiogenesis and the neuronal process since VEGF has been recognized as the survival factor for neuronal and endothelial cells. In the brain, VEGF has neuroprotective and neurotrophic properties; moreover, it helps in the maintenance of the blood-brain barrier, and in the lungs, VEGF plays a key role in alveolar development and surfactant synthesis. It is also critical for glomerular development in kidney and skeletal growth $[17,18]$; therefore, the blockage of VEGF may affect different organs of developing neonates.

In a case series of 13 patients who underwent IVB for ROP and were followed up for 5 years, only 1 patient showed a delay in growth and neurodevelopment and the others were within the normal range [19]. In the stated study, Denver Developmental Screening Test II (DDST 
II) was used to evaluate the growth and the neurodevelopment of the patients. It is noteworthy that no control group was included in the referred study. The results of the current study showed no developmental delay in neonates with ROP who were treated with IVB, as compared to the gestational age-matched control group. Furthermore, the ASQ was used as the screening test which performs well with children with prematurity $[13,14]$.

Another case series of 137 patients with a history of IVB for ROP treatment assessed the effect of intravitreal anti-VEGFs on neurodevelopment using the developmental-quotient (DQ) score. They followed the patients for 6 years and showed that there were no differences between the study population and the norms for the areas of personal social age, motor adaptive skills, gross motor skills, and language [20]. The same findings are repeated in another study by Chang et al. in a 2 year follow up using Bayley-II assessment tool [21]. In the present study, growth and development were evaluated by ASQ form in five areas (communication, fine motor, gross motor, problem-solving ability, and personal-social functioning). Nonetheless, in the Chang's study, the areas of personalsocial, motor adaptive skills, gross motor skills, and language were compared between the study population and the norms.

Recently, a study conducted by Morin et al. was published based on the data from the Canadian Neonatal Network and the Canadian Neonatal Follow-Up Network databases [22]. Out of 125 treated neonates, 27 cases received bevacizumab, and 98 newborns were treated by indirect laser therapy. The bevacizumab group had higher odds of severe neurodevelopmental disabilities at 18 months corrected age on the basis of the Bayley Scales of Infant and Toddler Development, compared to patients in indirect laser therapy. However, infants treated with bevacizumab appeared sicker upon admission. There was a trend toward a longer neonatal hospitalization and a lower proportion of females in the bevacizumab group. In the present study, there was no significant difference between the bevacizumab group and the treatment-naive controls regarding sex ratio and NICU stay. Furthermore, we excluded the patients with infectious diseases affecting the growth and neurodevelopmental status. In a retrospective study by Arima et al. neurodevelopmental examination was performed using the Kyoto Scale of Psychological Development (KSPD) examination tool. They found that the administration of IVB was significantly associated with neurodevelopmental delay in the Language-Social area but not Postural-Movement, Cognitive-Adaptive areas or overall developmental quotient (DQ) [23].

The major limitation in this study is the relatively short follow up of 18 month. Another drawback in this study is the lack of control group with laser treatment. Of course, attention to the results shows that in most basic and demographic factors, these two groups were matched, therefore, the absence of a laser-treated group will not be a defect for this study. The other shortcoming in this study was the higher gestational age of the control group. However, two groups had no significant difference in developmental scores despite the lower gestational age of treatment group who received IVB. Another defect of this study is low sample size. So it is recommended to perform more studies with higher sample sizes and longer follow ups as well as IQ testing later. Furthermore, assessment of cerebral palsy was not performed in this study. The abovementioned shortcomings should be considered in generalizability of findings in this study.

In conclusion, the results of the current study demonstrated that IVB exerted no effect on the growth and developmental process of ROP children. Nevertheless, it is recommended to perform prospective studies with longer follow-up and larger sample size to determine the long-term effect of intravitreal bevacizumab on systemic and ocular growth and development.

\section{Abbreviations}

ROP: Retinopathy of prematurity; VEGF: Vascular endothelial growth factor; IVB: Intravitreal bevacizumab; ASQ: Ages and stages questionnaire; DDST II: Denver Developmental Screening Test II; DQ: Developmental-quotient; BEAT-ROP: Bevacizumab Eliminates the Angiogenic Threat of Retinopathy of Prematurity; NICU: Neonatal intensive care unit.

\section{Acknowledgements}

The authors would like to thank Nasibeh Zaree, Fatemeh Neghabi, Mahtab Hejazi, Hasan Aryamehr; personnel of the ROP department and AliAkbar Sedighi; IT manager of Khatam Eye Hospital.

\section{Authors' contributions}

All the authors contributed significantly to this study, and all authors agree to be accountable for all aspects of the work. All authors read and approved the final manuscript.

\section{Funding}

The authors would like to acknowledge the financial support of the ViceChancellor of Research of Mashhad University of Medical Sciences for this research project (code: 930125). The funding organization had no role in the design or conduct of this research.

\section{Availability of data and materials}

The datasets generated and analyzed during the current study are available from the corresponding author on reasonable request.

\section{Declarations}

Ethics approval and consent to participate

The study protocol adhered to the tenets of the Declaration of Helsinki. All participants provided written informed consent before enrollment and the ethical aspects of the study were approved by the Regional Committee on Medical Ethics at Mashhad University of Medical Sciences, Mashhad, Iran (IR. MUMS.REC.1393.78). 


\section{Consent for publication}

Because the cases and controls are anonymous and were not depicted in the report, consent for publication is not applicable.

\section{Competing interests}

The authors declare that they have no competing interests.

\section{Author details}

${ }^{1}$ Eye Research Center, Mashhad University of Medical Sciences, Qarani Blvd, 9195965919 Mashhad, Iran. ${ }^{2}$ Neonatal Research Center, Mashhad University of Medical Sciences, Mashhad, Iran. ${ }^{3}$ Clinical Research Development Unit, Mashhad University of Medical Sciences, Mashhad, Iran.

Received: 10 September 2021 Accepted: 18 October 2021

Published online: 16 November 2021

\section{References}

1. Steinkuller PG, Du L, Gilbert C, Foster A, Collins ML, Coats DK. Childhood blindness. J Am Assoc Pediatr Ophthalmol Strabismus. 1999;3(1):26-32.

2. Abrishami M, Maemori G-A, Boskabadi H, Yaeghobi Z, Mafi-Nejad S, Abrishami M. Incidence and risk factors of retinopathy of prematurity in mashhad, northeast iran. Iran Red Crescent Med J. 2013:15(3):229.

3. International Committee for the Classification of Retinopathy of Prematurity. The international classification of retinopathy of prematurity revisited. Arch Ophthalmol. 2005;123(7):991-9.

4. Meng Q-Y, Cheng Y, Zhao M-W, Liang J-H. The process of retinal vascularization in retinopathy of prematurity after ranibizumab treatment in China. Int J Ophthalmol. 2019;12(7):1146

5. Mechoulam H, Pierce EA. Retinopathy of prematurity: molecular pathology and therapeutic strategies. Am J Pharmacogenomics. 2003:3(4):261-77.

6. Sonmez K, Drenser KA, Capone A Jr, Trese MT. Vitreous levels of stromal cell-derived factor 1 and vascular endothelial growth factor in patients with retinopathy of prematurity. Ophthalmology. 2008;115(6):1065-70 e1.

7. Sato T, Kusaka S, Shimojo H, Fujikado T. Vitreous levels of erythropoietin and vascular endothelial growth factor in eyes with retinopathy of prematurity. Ophthalmology. 2009;116(9):1599-603.

8. Mintz-Hittner HA, Kuffel RR Jr. Intravitreal injection of bevacizumab (avastin) for treatment of stage 3 retinopathy of prematurity in zone I or posterior zone II. Retina. 2008;28(6):831-8.

9. Wu WC, Yeh PT, Chen SN, Yang CM, Lai CC, Kuo HK. Effects and complications of bevacizumab use in patients with retinopathy of prematurity: a multicenter study in taiwan. Ophthalmology. 2011;118(1):176-83.

10. Sato T, Wada K, Arahori H, Kuno N, Imoto K, Iwahashi-Shima C, et al. Serum concentrations of bevacizumab (avastin) and vascular endothelial growth factor in infants with retinopathy of prematurity. Am J Ophthalmol. 2012;153(2):327-33 e1.

11. Miyake T, Sawada O, Kakinoki M, Sawada T, Kawamura H, Ogasawara $K$, et al. Pharmacokinetics of bevacizumab and its effect on vascular endothelial growth factor after intravitreal injection of bevacizumab in macaque eyes. Invest Ophthalmol Vis Sci. 2010;51(3):1606-8.

12. Squires J, Bricker D, Twombly E. Ages \& stages questionnaires ${ }^{\circledR}:$ socialemotional, second edition (ASQ $\left.{ }^{\circledR}: S E-2\right)$. A parent-completed child monitoring system for social-emotional behaviors. Baltimore, London, Sydney: Brookes Publishing Co; 2015.

13. Skellern CY, Rogers Y, O'Callaghan MJ. A parent-completed developmental questionnaire: follow up of ex-premature infants. J Paediatr Child Health. 2001:37(2):125-9.

14. Plomgaard AM, Hansen BM, Greisen G. Measuring developmental deficit in children born at gestational age less than 26 weeks using a parent-completed developmental questionnaire. Acta Paediatr. 2006:95(11):1488-94

15. Vameghi R, Sajedi F, Kraskian Mojembari A, Habiollahi A, Lornezhad HR, Delavar B. Cross-cultural adaptation, validation and standardization of ages and stages questionnaire (ASQ) in Iranian children. Iran J Public Health. 2013;42(5):522-8.

16. Mintz-Hittner HA, Kennedy KA, Chuang AZ, Group B-RC. Efficacy of intravitreal bevacizumab for stage $3+$ retinopathy of prematurity. N Engl J Med. 2011;364(7):603-15.

17. Hapsari D, Sitorus RS. Intravitreal bevacizumab in retinopathy of prematurity: inject or not? Asia Pac J Ophthalmol. 2014;3(6):368-78.

18. Darlow BA, Ells AL, Gilbert CE, Gole GA, Quinn GE. Are we there yet? Bevacizumab therapy for retinopathy of prematurity. Arch Dis Child Fetal Neonatal Ed. 2013;98(2):F170-4.

19. Martinez-Castellanos MA, Schwartz S, Hernandez-Rojas ML, Kon-Jara VA, Garcia-Aguirre G, Guerrero-Naranjo JL, et al. Long-term effect of antiangiogenic therapy for retinopathy of prematurity up to 5 years of follow-up. Retina. 2013;33(2):329-38.

20. Wallace DK, Wu KY. Current and future trends in treatment of severe retinopathy of prematurity. Clin Perinatol. 2013:40(2):297-310.

21. Chang Y-S, Chen Y-T, Lai T-T, Chou H-C, Chen C-Y, Hsieh W-S, et al. Involution of retinopathy of prematurity and neurodevelopmental outcomes after intravitreal bevacizumab treatment. PloS ONE. 2019;14(10): e0223972.

22. Morin J, Luu TM, Superstein R, Ospina LH, Lefebvre F, Simard M-N, et al. Neurodevelopmental outcomes following bevacizumab injections for retinopathy of prematurity. Pediatrics. 2016. https://doi.org/10.1542/peds. 2015-3218

23. Arima M, Akiyama M, Fujiwara K, Mori Y, Inoue H, Seki E, et al. Neurodevelopmental outcomes following intravitreal bevacizumab injection in Japanese preterm infants with type 1 retinopathy of prematurity. PloS ONE. 2020;15(3): e0230678.

\section{Publisher's Note}

Springer Nature remains neutral with regard to jurisdictional claims in published maps and institutional affiliations.
Ready to submit your research? Choose BMC and benefit from:

- fast, convenient online submission

- thorough peer review by experienced researchers in your field

- rapid publication on acceptance

- support for research data, including large and complex data types

- gold Open Access which fosters wider collaboration and increased citations

- maximum visibility for your research: over $100 \mathrm{M}$ website views per year

At BMC, research is always in progress.

Learn more biomedcentral.com/submissions 